\title{
Newborn birth weight: a trend towards positive paradigm shift in rural central India
}

\author{
Surekha A. Tayade*, Neha Gangane, Jaya Kore, Noopur Singh, Shalaka Harne
}

Department of Obstetrics and Gynecology, Mahatma Gandhi Institute of Medical Sciences, Sewagram, Wardha, Maharashtra, India

Received: 31 December 2017

Accepted: 31 January 2018

*Correspondence:

Dr. Surekha A. Tayade,

E-mail: stayade@mgims.ac.in

Copyright: () the author(s), publisher and licensee Medip Academy. This is an open-access article distributed under the terms of the Creative Commons Attribution Non-Commercial License, which permits unrestricted non-commercial use, distribution, and reproduction in any medium, provided the original work is properly cited.

\begin{abstract}
Background: Birth weight is one of the important determinants of neonatal wellbeing. It has many determinants including maternal nutritional status and gestational age. Low birth weight is associated with high neonatal and childhood mortality and morbidity. Over the years the birth weight is showing the increasing trend in developing countries like India. The study aimed at finding out the changing pattern of birth weight over a decade in rural India.

Methods: Retrospective data of 43,114 births was collected through hospital information system. Neonatal birth weight was analyzed over a period of 10 years from 2007-2016. Demographic data was studied to study the determinants.

Results: Over the period of 10 years, proportion of newborn with low birth weight (below 2500 grams) declined from $56.35 \%$ to $43.65 \%$. The rise in mean birth weight was 147 gram in male infant and 114 grams in female. There was overall reduction in proportion of very low birth weight and extremely low birth weight babies. A linear relationship was observed between improved birth weight, socio economic status, age at marriage and maternal weight gain during pregnancy.

Conclusions: A positive trend towards improved newborn birth weight was observed in study site of rural central India. Better antenatal care, improved maternal nutrition and improved social status of women in the community are the determinants found to have a positive correlation.
\end{abstract}

Keywords: Maternal determinants, Newborn birth weight, Newborn health, Rural area

\section{INTRODUCTION}

Birth weight is the first weight of the foetus or newborn obtained after birth. It is one of the most important factor for estimating the maturity of the newborn, evaluating intrauterine growth and development and is an important indicator of its vulnerability for childhood illnesses and survival ability. ${ }^{1}$

Babies with a birth weight of less than 2500 grams, irrespective of the period of their gestation are termed as
Low Birth Weight (LBW) babies. Despite consistent efforts to improve the quality of maternal and child health, more than twenty million LBW babies are born every year throughout the world. ${ }^{2}$

In both, the developed and developing countries low birth weight is the most important factor that affects perinatal mortality, neonatal mortality, infant mortality and infant and childhood morbidity. ${ }^{3}$ LBW is considered to be associated with a greater risk of early infant death than is associated with normal birth weight. ${ }^{2}$ 
Furthermore, it is a significant factor associated with higher probabilities of infections, greater susceptibility to childhood illnesses, long-term physical and mental deficiencies, behavioural and learning problems and psychosocial I disabilities during childhood. ${ }^{4} \mathrm{LBW}$ and preterm birth are major determinants of perinatal survival, infant morbidity and mortality as well as risk of developmental disabilities and illnesses throughout future lives. 5

In 2013, nearly 22 million newborns-an estimated 16 per cent of all babies born globally that year-had low birth weight (UNICEF). Among regions, South Asia has the highest incidence of low birth weight, with one in four newborns weighing less than 2,500 grams.

The data indicate that the incidence of low birth weight remained unchanged from the 1990s to 2010 in both subSaharan Africa and Asia. More than 20 million infants worldwide, representing 15.5 per cent of all births, are born with low birth weight, 95.6 per cent of them in developing countries.

The proportion of low birth weight in developing countries ( 16.5 per cent) is more than double the level in developed regions ( 7 per cent). UNICEF has reported the $30 \%$ incidence of low birth weight in Bangladesh was, $26 \%$ in India, $21 \%$ in Pakistan and $25 \%$ in Sri Lanka. ${ }^{5}$ In India, NFHS reported that the proportion of low birth weight babies about $23 \%$ for rural and $19 \%$ for urban population. ${ }^{6}$

Low weight at birth is either the result of preterm or fetal growth restriction. Many factors affect the duration of gestation and foetal growth, and thus, the birth weight. The determinants of LBW can be genetic, constitutional, obstetric, nutritional, related to maternal morbidities in the antenatal period, toxic exposure-related, and linked to antenatal care. Other factors include smoking, maternal age, birth spacing, antenatal care, anemia, genital infections, maternal ill health and stress. ${ }^{7}$

Birth weight is also affected to a great extent by the mother's own foetal growth and her diet from birth to pregnancy, and thus, her body composition at conception. Mothers in deprived socio-economic conditions frequently have low birth weight infants (UNICEF). ${ }^{6}$ Thus, the present study was carried out to analyze the change in new-born birth weight in a rural area over a decade and examine the determinants.

\section{METHODS}

This was a retrospective observational study carried out at Kasturba Hospital, attached to a tertiary care rural institute of central India situated in eastern Maharashtra. Kasturba hospital a 1000 bedded health care unit and is part of MGIMS, Sewagram, an institution consistently being ranked among the top 20 medical schools in the country. The state has a maternal mortality ratio of 68 per one lakh live births (SRS 2011-13) and the health system is striving hard to provide quality maternity care and reduce maternal mortality further. MGIMS is a centre of excellence with a dedicated team of health care providers and hence most of the complicated maternal cases from the surrounding district's and even adjacent states of Andhra Pradesh and Madhya Pradesh are referred to MGIMS.

The referred cases at institution has further increased due to improved infrastructure ( $\mathrm{MCH}$ wing) and availability of ICU facilities. MGIMS, Sewagram is located in a village and our health professionals are conscious of the fact that our work ought to be guided by the felt needs and unvoiced concerns of communities we serve.

The Department of Obstetrics and Gynecology (OBGY) believes in providing quality services with a human touch to all the rural and urban women visiting the outdoor and indoor sections. The department have facilities for antenatal, postnatal, gynecological care as well as critical care, caters to around 5000 deliveries per year and has adopted 56 surrounding villages for providing community reproductive health. ANMs and AASHAs provide antenatal care at doorstep.

High risk pregnancy is diagnosed and timely referral is practiced. Birth preparedness and complication readiness is the mainstay of antenatal counselling. The labour room is well equipped and provides high quality intrapartum services.

The nurses are adequately trained to record birth weight using UNICEF infant weighing machine (lever balance type) to the nearest' $20 \mathrm{~g}$ after correcting the zero error. The weighing machines are being checked periodically and standardized. The unit had high quality neonatal care facilities with a dedicated staff.

All the data of patients is entered in Hospital Information System (HIS) since 2007 and the system is completely paperless. In the present study, data related to birth weight of newborn babies for ten years duration, from January 2007 to December 2016 was collected through HIS. The study included all live born babies irrespective of gestational age, parity or multi-fetal pregnancy.

Socio-demographic data was collected from records. Age of mother, socioeconomic status, education, area of residence, pre-pregnancy weight and weight gain during pregnancy were noted. Data was entered into excel sheet and analyzed using SPSS software.

\section{RESULTS}

During the study period of 10 years, there were 43,114 births at Kasturba Hospital. In the year 2007, 56.35\% babies were born with low birth weight compared to $45.06 \%$ in 2016 which signifies a significant drop ( $p$ value $<0.05)$ (Table 1). 
Table 1: New born birth weight over a decade.

\begin{tabular}{|lllll|}
\multirow{2}{*}{ Year } & \multicolumn{3}{l}{ Newborn Birth Weight } \\
& Below 2500 grams & \multicolumn{2}{l|}{ Above 2500 grams } \\
\hline & No & \% & No & \% \\
\hline 2007 & 2198 & 56.35 & 1702 & 43.64 \\
\hline 2008 & 2150 & 50.48 & 2109 & 49.51 \\
\hline 2009 & 2344 & 51.16 & 2237 & 48.83 \\
\hline 2010 & 2270 & 48.01 & 2459 & 52 \\
\hline 2011 & 2330 & 51.07 & 2232 & 48.92 \\
\hline 2012 & 1926 & 47.01 & 2171 & 52.98 \\
\hline 2013 & 1984 & 46.02 & 2327 & 53.97 \\
\hline 2014 & 2040 & 47.27 & 2275 & 52.72 \\
\hline 2015 & 1970 & 43.84 & 2523 & 46.15 \\
\hline 2016 & 2058 & 45.06 & 2509 & 54.92 \\
\hline
\end{tabular}

The proportion of babies with birth weight above 2500 grams rose from $43.64 \%$ in 2007 to $54.92 \%$ in 2016 . The mean birth weight of male babies in 2007 was 2443 grams in 2007 which increased to 2590 grams by 2016 with a significant difference (chi square-17.25, $\mathrm{p}$ value $<0.05)$. The mean birth weight of female babies in year 2007 was 2440 grams which increased to 2554 grams by 2016 (chi square-14.20, p value <0.05). The increase in mean birth weight for male and female babies was by 147 grams and 114 grams respectively during study period of 10 years (Table 2 ).

Table 2: Change in mean birth weight over a decade.

\begin{tabular}{|lll|} 
Year & $\begin{array}{l}\text { Mean birth } \\
\text { weight in grams } \\
\text { (Male) }\end{array}$ & $\begin{array}{l}\text { Mean birth } \\
\text { weight in grams } \\
\text { (Female) }\end{array}$ \\
\hline 2007 & 2443 & 2440 \\
\hline 2016 & 2590 & 2554 \\
\hline $\begin{array}{l}\text { Rise in birth } \\
\text { weight }\end{array}$ & 147 grams & 114 grams \\
\hline
\end{tabular}

The proportion of babies born with extremely low birth weight $(<1000$ grams), very low birth weight $(<1500$ grams) and low birth weight $(<2500$ grams $)$ reduced during the 10 year study period and correspondingly those with weight above 2500 grams and above 3000 grams increased (Table 3 ).

Table 3: Change in new born birth weight distribution over a decade.

\begin{tabular}{|lllll|}
\hline $\begin{array}{l}\text { New born birth } \\
\text { weight }\end{array}$ & \multicolumn{2}{c}{ Year 2007 } & \multicolumn{2}{c}{ Year 2016} \\
\hline Value & No. & \% & No. & $\%$ \\
\hline <1000 grams & 117 & 3 & 92 & 2.01 \\
\hline 1000-1500 grams & 326 & 8.35 & 230 & 5.03 \\
\hline 1501-2500 grams & 1755 & 45.02 & 1820 & 39.85 \\
\hline 2501-3000 grams & 1259 & 32.28 & 1970 & 43.13 \\
\hline >3000grams & 443 & 11.35 & 455 & 9.96 \\
\hline
\end{tabular}

Over a period of ten years, the average age at marriage for girls increased from 18 years to 20.5 years and the age at first pregnancy increased from 18.5 years to 21 years (Table 4).

Table 4: Change in age at marriage for girls and age at first pregnancy.

\begin{tabular}{|lll|} 
Year & $\begin{array}{l}\text { Average age at } \\
\text { marriage in years }\end{array}$ & $\begin{array}{l}\text { Age at first } \\
\text { pregnancy in years }\end{array}$ \\
\hline 2007 & 18 & 18.9 \\
\hline 2016 & 20.5 & 21 \\
\hline
\end{tabular}

Significant improvement in the socio economic status of pregnant women was observed during the study period (Table 5).

Table 5: Socioeconomic status of pregnant women.

\begin{tabular}{|c|c|c|c|c|c|}
\hline \multirow{2}{*}{$\begin{array}{l}\text { Socio-economic } \\
\text { status } \\
\text { (Modified } \\
\text { Prasad BG } \\
\text { classification) }\end{array}$} & \multicolumn{4}{|l|}{ Year } & \multirow[t]{2}{*}{$\begin{array}{l}P \\
\text { value }\end{array}$} \\
\hline & 2007 & & 2016 & & \\
\hline Upper & 18 & $0.46 \%$ & 70 & $1.53 \%$ & $<0.05$ \\
\hline Upper Middle & 214 & $5.48 \%$ & 375 & $8.21 \%$ & $<0.05$ \\
\hline Middle & 624 & $16 \%$ & 924 & $20.23 \%$ & $<0.05$ \\
\hline Lower Middle & 1133 & $29.05 \%$ & 1235 & $27.04 \%$ & $<0.05$ \\
\hline Lower & 1911 & $49.00 \%$ & 1963 & $42.98 \%$ & $<0.05$ \\
\hline
\end{tabular}

The pre-pregnancy weight of women improved significantly. The percentage of underweight $(<40 \mathrm{~kg})$ reduced from $10.7 \%$ to $3.8 \%$ (Table 6 ).

Table 6: Change in pre pregnancy weight over the study period.

\begin{tabular}{|lllll|}
\hline Weight in Kg & \multicolumn{2}{c}{ Year 2007} & \multicolumn{2}{c|}{ Year 2016} \\
\hline Value & No. & \% & No. & \% \\
\hline Below 40 & 397 & 10.17 & 174 & 3.80 \\
\hline $40-50$ & 2145 & 55 & 1826 & 39.98 \\
\hline $50-60$ & 1050 & 26.92 & 1740 & 38 \\
\hline $60-70$ & 277 & 7.10 & 553 & 12.10 \\
\hline Above 70 & 31 & 0.79 & 274 & 5.99 \\
\hline
\end{tabular}

The average weight gain during pregnancy increased over the period of 10 years. The percentage of pregnant women with weight gain of more than $10 \mathrm{~kg}$ increased from $11.06 \%$ to $23.35 \%$ (Table 7 ).

Table 7: Change in average weight gain during pregnancy over a decade.

\begin{tabular}{|c|c|c|c|c|}
\hline $\begin{array}{l}\text { Average weight gain } \\
\text { during pregnancy }\end{array}$ & \multicolumn{2}{|c|}{ Year 2007} & \multicolumn{2}{|c|}{ Year 2016} \\
\hline Value & No. & $\%$ & No. & $\%$ \\
\hline$<5 \mathrm{Kg}$ & 109 & 2.79 & 10 & 0.21 \\
\hline $5-8 \mathrm{Kg}$ & 1400 & 35.89 & 584 & 12.78 \\
\hline $8-10 \mathrm{Kg}$ & 1959 & 50.23 & 2931 & 64.17 \\
\hline $10-12 \mathrm{Kg}$ & 308 & 7.89 & 711 & 15.56 \\
\hline$>12 \mathrm{Kg}$ & 124 & 3.17 & 356 & 7.79 \\
\hline
\end{tabular}




\section{DISCUSSION}

Low birth weight has long been used as an important public health indicator. Globally, the indicator is a good summary measure of a multifaceted public health problem that includes long-term maternal malnutrition, ill health, hard work and poor pregnancy health care. A World Fit for Children,' the Declaration and Plan of Action adopted at the United Nations General Assembly Special Session on Children in 2002 has a goal of reducing low birth weight incidence by at least one third between 2000 and 2010. This also forms an important contribution to the Millennium Development Goal (MDG) for reducing child mortality. ${ }^{6}$ We need to ensure a healthy start in life for children by making certain that women commence pregnancy healthy and well-nourished and go through pregnancy and childbirth safely. ${ }^{8}$

The present large study of 43,114 newborns was carried out in a tertiary care institute catering to the reproductive health of rural masses. The community here has a high proportion of women with nutritional anemia and overall has undernourished population in the villages. Adolescent girls are also undernourished and anemic. These girls are married off early as per tradition and thus proportion of teenage pregnancies is common. As the pre pregnancy weight of these girls is low, low birth weight babies are born to these undernourished mothers. The incidence of lower genital tract and urinary tract infection also is high in them resulting in preterm labor and low birth weight babies. Other factors such as hypertensive disorders of pregnancy also result in fetal growth restriction and rise in low birth weight babies. Over the years a positive trend has been observed in the overall social structure of the inmates of the community.

Overall improvement has been noticed in the maternal health status, thus positively affecting the outcome of pregnancy. Female literacy has increased to a considerable extent, thus affecting the age of marriage positively. The educated girls understand the importance of good nutrition for themselves and their families. There is also better use of contraception by the couples and delay in the age of first pregnancy. Thus, teenage pregnancies and their complications have reduced. Better nutrition, reduced genital infections and better attendance in antenatal care unit has overall improved the maternal and fetal outcome. Thus overall there has been a rise in the mean birth of new borns over the decade. In a study by Celine et al, the proportion of low birth weight of new born babies from 2000-2001 to 2008-2009 was increased from $17.8 \%$ to $25.09 \%(\mathrm{P}<0.0001)$ showing a negative trend. ${ }^{9}$ However, Akoijam et al reported that new born birth weight was increasing with the passing years and that low birth weight showed significant association with parity, age of the mother, booking status, hemoglobin level, and literacy of the mother. ${ }^{10}$ Teshome et al found that the mean birth weight and percentage of low birth weight were significantly different in both sexes ( $p$ $<0.0001)$. The birth weight increased as parity and length of gestation increased. As maternal age and maternal height increased, so did the neonatal birth weights. ${ }^{11}$ Gebremedhin et al also revealed that maternal weight, gestational age, residence, and presence of chronic medical illness were found to be significant predictors for low birth weight. The prevalence of low birth weight was found to be $14.6 \%$, which is similar with the LBW levels of sub-Saharan Africa countries. ${ }^{12}$

Improved socio-economic status means more attention and spending on nutrition and health. ${ }^{13}$ Adoption of small family norm, better use of contraceptives, birth spacing, and improvement of nutritional anemia all has contributed to improved maternal health. The pre pregnancy weight and pregnancy weight gain is better and thus intrauterine growth of fetus has improved. Birth weight is affected to a great extent by the mother's own foetal growth and her diet from birth to pregnancy, and thus, her body composition at conception, thus improved pre pregnancy weight has an important role to play in the improvement in new born weight. Similarly, the physical environment of the mother and fetus plays an important role in determining the infant's birth weight and future health. Girls weigh less than boys, firstborn infants are lighter than subsequent infants, and twins weigh less than singletons. ${ }^{14}$

Pregnant mother's nutrition and diet, lifestyle, and other exposures (e.g., malaria, HIV or syphilis), or complications such as hypertension can affect foetal growth and development, as well as the duration of pregnancy. ${ }^{15}$ Mothers in deprived socio-economic conditions frequently have low birth weight infants. In those settings, the infant's low birth weight stems primarily from the mother's poor nutrition and health over a long period of time, including during pregnancy, the high prevalence of specific and non-specific infections, or from pregnancy complications underpinned by poverty. Physically demanding work during pregnancy also contributes to poor foetal growth. ${ }^{6}$ Thus, in the present study improved social condition resulted in improvement in new born weight. However, in study by Teshome et al house hold income, maternal education and antenatal care use were not found to influence the mean birth weight. On the other hand, maternal age, maternal height, parity and length of gestation had a positive correlation with mean birth weight.

\section{CONCLUSION}

A positive paradigm shift towards improvement in newborn birth weight was seen in rural central India. Maternal Age, Age at marriage, age at first pregnancy, socioeconomic status, pre-pregnancy weight and pregnancy weight gain had positive correlation with birth weight. The improvement in socioeconomic status, women's status in society, literacy and improvement of nutritional status of women are found to be the determinants. Correction of maternal anemia, high risk pregnancy identification, good antenatal care and overall 
improvement in socioeconomic status have improved neonatal outcome.

Funding: No funding sources Conflict of interest: None declared

Ethical approval: The study was approved by the Institutional Ethics Committee

\section{REFERENCES}

1. Behrman RE. Preterm birth: causes, consequences, and prevention. Washigton DC: Institute of Medicine (US) Committee on Understanding Premature Birth and Assuring Healthy Outcomes;2007.

2. Yadav DK, Chaudhary U, Shrestha N. Risk factors associated with low birth weight. J Nepal Health Res Council. 2011;9(2):159-64.

3. Bangal VB, Gavhane SP, Gagare SD, Aher KH, Bhavsar DK, Verma PR. Changing pattern of birth weight over a decade in rural India. 2017;6(10):6.

4. Assefa N, Berhane Y, Worku A. Wealth status, mid upper arm circumference (MUAC) and antenatal care (ANC) are determinants for low birth weight in Kersa, Ethiopia. PloS one. 2012;7(6):e39957.

5. Zeleke BM, Zelalem M, Mohammed N. Incidence and correlates of low birth weight at a referral hospital in Northwest Ethiopia. Pan Afr Med J. 2012;12(4).

6. WHO U. Low birth weight: country, regional and global estimates. New York: UNICEF;2004.

7. Jayant DD, Phalke D, Peeyuusha D, Sushen B. Maternal risk factors for low birth weight neonates: A hospital based case-control study in rural area of Western Maharashtra, India. Natl J Commun Med. 2011 Dec;2(3):394-8.

8. Khushboo J, Najam K, Athar A, Anees A, Haroon K. Effect of utilization of antenatal services on pregnancy outcome in Aligarh: a community based study. Indian J Commun Health. 2016;28(1):40-4.

9. Celine TM, Antony J. Pattern of birth weight of new born babies at a tertiary care level. Int J Prevent Med. 2012;3(5):375-6.

10. Akoijam BS, Thangjam ND, Singh KT, Devi SR, Devi RK. Birth weight pattern in the only referral teaching hospital in Manipur. Indian J Public Health. 2006;50(4):220-4.

11. Teshome D, Telahun T, Solomon D, Abdulhamid I. A study on birth weight in a teaching-referral hospital, Gondar, Ethiopia. Cent Afr J Med. 2006;52(1-2):8-11.

12. Gebremedhin M, Ambaw F, Admassu E, Berhane H. Maternal associated factors of low birth weight: a hospital based cross-sectional mixed study in Tigray, Northern Ethiopia. BMC Pregnancy Childbirth. 2015;15(1):222.

13. Braveman P, Gottlieb L. The social determinants of health: it's time to consider the causes of the causes. Public Health Reports. 2014;129(Suppl 2):19-31.

14. Kandel KP, Kafle S. Risk factors associated with low birth weight among deliveries at Bharatpur Hospital. J Nepal Health Res Council. 2017;15(2):169-73.

15. Capra L, Tezza G, Mazzei F, Boner AL. The origins of health and disease: the influence of maternal diseases and lifestyle during gestation. Italian $\mathbf{J}$ Pediatr. 2013;39:7.

Cite this article as: Tayade SA, Gangane N, Kore J, Singh N, Harne S. Newborn birth weight: a trend towards positive paradigm shift in rural central India. Int J Reprod Contracept Obstet Gynecol 2018;7:1024-8. 